Artigo

\title{
Sobre o estudar com professoras que ensinam matemática nos anos iniciais do Ensino Fundamental: a ideia de uma formação-trilha
}

\section{About studying with teachers who teach mathematics in the early years of elementary school: the idea of a trail formation}

A cerca de estudiar con profesoras que enseñan matemática en los primeros grados de la primaria: una idea de formación-sendero

\author{
Jussara Brigo ${ }^{1}$ \\ [0000-0002-5665-7939] \\ Cláudia Regina Flores ${ }^{2}$ \\ [0000-0003-2351-5712] \\ Débora Regina Wagner ${ }^{3}$ \\ [0000-0002-1588-8853]
}

\begin{abstract}
Resumo
Este artigo problematiza o estudar com um grupo de professoras que ensinam matemática nos anos iniciais do Ensino Fundamental, compondo um tipo de formação que se denominou pelo ato de caminhar, de trilhar. Um trilhar que, pelas fadigas do andar nos trilhos, nos convoca a fugir de caminhos marcados-cristalizados, incitando-nos a parar, a deter-se, a perder-se, a furar espaços, a habitar outros, a pensar. Disto fazer emergir pensamentos, ações, forças, resistências, palavras, ficções e reinvenções de coisas que abrem fendas com os próprios pés, e traçam trilhas errantes em outros espaços. Daí a estratégia de um tipo de formação que se dá antes pelo verbo estudar, do que pelo formar. Estudar como um fazer-se trilha, trilhar-se. E, assim, intensificando a percepção de que a trilha é uma espécie de corpo-estudo que está à espera de que algo aconteça, que algo inter-venha. Algo que não é mais da ordem do planejado e esperado, da formação, mas de uma prática e de um exercício educacional de liberdade e silêncio. Pelo estudar exercita-se o silêncio, habita-se espaços e trajetos, cria-se trilhas, num ato solitário e ou em (com)-panhia, onde matemática e o ensino da matemática aparecem como problemáticas de estudo.
\end{abstract}

Palavras-chave: Estudar. Espaço de (Form)-ação. Grupo de Estudos. Anos Iniciais do Ensino Fundamental. Pedagogia.

Abstract: This article problematizes studying with a group of teachers who teach mathematics in the early years of elementary school, composing a type of training that was called walking, walking. A trail that, due to the fatigue of walking on the tracks, calls us to flee from marked crystallized paths, inciting us to stop, to stop, to lose ourselves, to pierce spaces, to inhabit others, to think. This gives rise to

\footnotetext{
${ }^{1}$ brigojussara@gmail.com, Doutora em Educação Científica e Tecnológica, Professora de Matemática, Prefeitura Municipal de Florianópolis, Florianópolis/SC/Brasil.

2 claudia.flores@ufsc.br, Doutora em Educação, Professora, Departamento de Metodologia de Ensino, Centro de Ciências da Educação, e Programa de Pós-Graduação em Educação Científica e Tecnológica da Universidade Federal de Santa Catarina, Florianópolis/SC/Brasil.

3 debora.wagner@ufsc.br, Doutora em Educação Científica e Tecnológica, Professora, Departamento de Metodologia de Ensino, Centro de Ciências da Educação, Universidade Federal de Santa Catarina, Florianópolis/SC/Brasil.
} 
thoughts, actions, forces, resistances, words, fictions and reinventions of things that open crevices with their own feet, and trace errant trails in other spaces. Hence the strategy of a type of training that is given more by the verb to study, than by training. Study as a trail, trail. And, thus, intensifying the perception that the trail is a kind of body-study that is waiting for something to happen, for something to intervene. Something that is no longer in the order of what was planned and expected, of training, but of an educational practice and exercise of freedom and silence. By studying, silence is exercised, spaces and paths are inhabited, trails are created, in a solitary act and or in company, where mathematics and the teaching of mathematics appear as study problems.

Keywords: To study. Training Space. Study group. Early Years of Elementary School. Pedagogy.

Resumen: Este artículo problematiza el estudio con un grupo de profesoras que enseñan matemáticas en los primeros años de la escuela primaria, componiendo un tipo de entrenamiento que se llamaba caminar, caminar. Un sendero que, debido a la fatiga de caminar en las pistas, nos llama a huir de los caminos cristalizados-marcados, incitándonos a detenernos, detenernos, perdernos, perforar espacios, habitar a otros, pensar. Esto da lugar a pensamientos, acciones, fuerzas, resistencias, palabras, ficciones y reinvenciones de cosas que abren grietas con sus propios pies y trazan senderos errantes en otros espacios. De ahí la estrategia de un tipo de entrenamiento que se da más por el verbo estudiar que por el entrenamiento. Estudiar como un sendero, sendero. Y, por lo tanto, intensificando la percepción de que el sendero es una especie de cuerpo de estudio que está esperando que algo suceda, que algo intervenga. Algo que ya no está en el orden de lo planeado y esperado, de la capacitación, sino de una práctica educativa y ejercicio de libertad y silencio. Al estudiar, se practica el silencio, se habitan espacios y caminos, se crean senderos, en un acto solitario y / o en compañía, donde las matemáticas y la enseñanza de las matemáticas aparecen como problemas de estudio.

Palabras claves: Estudiar. Espacio de entrenamiento. Grupo de Estudios. Primeros años de la escuela primaria. Pedagogía.

\section{1 À guisa de introduzir: das fadigas do "formar-modelar"}

Em uma trilha os caminhos são múltiplos. Pode-se fugir dos trilhos e dos caminhos já traçados, orientados, e por fim, se marcados, ficam cristalizados, naturalizados. Entretanto, cada trilheira(o) que caminha pode fazer a sua travessia e as suas paragens. Há potência do/no livre. Cada um pode parar onde quiser e nesse entremeio, de caminhar e parar, muitas coisas podem emergir. Mas, talvez, pelo hábito de seguir, um medo se instaura: perder-se dos demais, perder-se do condutor, perder-se do caminho marcado, perder-se das regras, perderse do conteúdo e dos conceitos da matemática. Ora, eis que, aqui, para nós, algumas paragens tomam os entremeios como lócus de potência para as afeições, vertentes, buracos, trincheiras, valetas, cavernas e abismos, que acontecem na vida de uma professora-trilheirapesquisadora, que caminhou com outras professoras-trilheiras na Ilha (Formação de Professores). Daí que o perder-se pode ser a potência para o encontrar-ser em estudo, no estudo, pelo estudar.

Mas, antes disso, fatigamos. Nessa fadiga a emergência, da cristalização de certos ideários que atravessam a formação continuada de professores de matemática, desperta em nós o interesse em expor e problematizar um modelo de formação que está posto, enraizado (BRIGO; FLORES, 2019). Em especial, ao problematizar os documentos normativos que tratam da formação continuada, as autoras apresentaram um modelo cíclico que parte do professor 
(sujeito) na busca por um professor desejado (sujeito fabricado). Invenção ancorada em certos dispositivos que engloba discursos, decisões regulamentares, leis, técnicas e estratégias" (FOUCAULT, 2009a) que, segundo as autoras, disparam ecos de que o sujeito professor(a) repense, reflita o seu processo pedagógico, neste processo de reflexão ele deve buscar um "aperfeiçoamento" (melhoria, aprimoramento e evolução) acerca de seus saberes e valores junto ao coletivo de professores e das organizações que ofertam formação. Com isso, parece que sempre haverá alguém e/ou alguma coisa (um formador, uma organização, um documento normativo, um livro guia ou qualquer outra coisa) que explique ao professor o que é mais adequado (mais proveitoso, vantajoso, motivador, inovador, mais... mais... etc...). Enfim, tantas outras coisas que se afirmam para que o professor esteja apto para o "mercado" e para exercer sua "profissão".

Cabe sinalizar que a palavra "profissão", comumente utilizada no contexto pedagógico e capturada pelo mercado de trabalho, se encontra contaminada por ideologias que não valorizam as mãos e as maneiras de ser e estar professor(a). Fala-se em "ofício especializado" que legitima alguém a fazer alguma coisa, ou seja, estigmatizado "[...] pela ideologia do profissionalismo e da profissionalização. É aí, nas profissões profissionalizadas, que e se deslocaram das competências, das capacidades, dos saberes técnicos e dos modos do fazer mais sofisticado e bem feito" (LARROSA; RECHIA, 2018, p. 319). Disto ecoam-se: "aperfeiçoamento", "profissionalismo", "modos de fazer mais sofisticado", "modos de fazer bem feito", "modos de fazer mais eficaz", "modos de fazer perfeito", "modos-de-fazer" e "modos-de-fabricar". Ecos que assombram as mãos e as maneiras de cada professor(a) e fazem com que muitos espaços de formação continuada se caracterizem como um processo de racionalização, conscientização e disciplinamento dos(as) professores(as), desviando-se, assim, dos processos de afetação, sensibilização, ruptura, recriação e reinvenção, os quais despertam o desejo e a liberdade de formar-se.

É dessa fadiga, desses processos cíclicos que nos causam vertigens, que somos desafiadas a invenção de outros modos de habitar o espaço da formação de professores(as) junto a Educação Matemática. A exemplo disso, citamos a pesquisa de Jussara Brigo (2020) que convida um grupo de professoras, que atuam na Educação Básica e ensinam matemática nos anos iniciais do ensino fundamental, para pairar em busca de outros deslocamentos (lentos, artesanais, imprevistos, errantes...). Um convite que foi feito, não para se unir em colaboração, mas para se enfrentar com a "ação" de fugir de um tipo sujeito (professor(a)).

Ora, este tipo-sujeito professor, resultante de um tipo-formação, caracterizada pelo fato de que ele (a) (o professor ou a professora), não pode perder tempo e não pode ficar para trás em relação aos demais. E conformando-se com seu ofício ${ }^{4}$ (trabalho), trata-se como mercadoria, que pensa que modelos-padrões (de aprendizagem, de formação, de escola, de mundo, de vida) devem ser seguidos e reproduzidos - nos âmbitos local ou global -, e nos quais o currículo e a escola se organiza em "pacotes" cada vez mais numerosos e curtos eixos, objetivos (habilidades e competências), anos/séries e bimestre. Percebe-se, assim, que disso vivem "sempre aceleradas", sentem-se cobrados(as), com a sensação de que nunca

\footnotetext{
4 “Não se deseja ter a função de formar alguém, não se interessa por uma forma padrão de professor alfabetizador que ensina matemática, mas se buscou valorizar as maneiras de cada um exercer seu ofício. Logo, tentou-se criar um espaço de abertura, onde sujeitos e saberes pudessem se relacionar mediante uma igualdade de inteligência. Desloca-se de um professor-padrão para um professor-artesão." (BRIGO, 2020, p. 29-30).
} 
vencerão os objetivos propostos para cada ano, e de que "nada lhes acontece" (LARROSA, 2017). Este tipo de formação constitui-se o que Brigo (2020) denominou por llha. A Ilha dos Explicadores Desiguais, e ou, Ilha dos Formadores.

Essa formação continuada, Ilha, com o propósito de formar-modular professores nos afeta e nos instiga a suspender "processos de racionalização, conscientização e disciplinamento" (LEITE, 2011, p. 42). E pensar que, com isso, possa ser possível abrir picadas, cavar buracos na própria Ilha, descobrir poços e adentrar cavernas com o pertencimento de vidas e mundos. Na potência da própria palavra, existir outras ilhas dentro da própria llha. Com Foucault (1990), pensamos que "certos" dispositivos regulam as condutas dos professores de matemática em direção a um "modelo-padrão", e que estes precisam ser desnaturalizados, problematizados e, por que não, furados.

Daí que se demarca um novo trilhar na llha: é preciso fazer (form)-ação ${ }^{5}$ nas formações continuadas de professores que ensinam matemática. Para isso, tentou-se inventar um espaço outro, um tipo de contradispositivo da formação que vê no caminhar e no estudar a possibilidade de "[...] imaginar outros espaços, onde os sujeitos possam andar com os próprios pés e per-correr suas próprias trilhas, quando não nos contentamos em sermos apenas professoras que ensinam matemática, e sim, que podemos fazer de todo o trabalho um meio de expressão"(BRIGO, 2020, p. 179).

Em uma trilha muitas coisas podem acontecer.

Em uma trilha-pesquisa muitas coisas podem acontecer.

Em uma trilha-pesquisa com professoras ${ }^{6}$ que ensinam matemática nos anos iniciais do Ensino Fundamental muitas coisas podem acontecer. É preciso estar atento ao caminho que se pisa, aos detalhes, aos pormenores, às miudezas, às invisibilidades, ... "A pesquisacaminhante não é um modelo de trilhar, não é um modelo de caminhar, e se distancia de uma indicação de verdade, é travessia-múltipla. Travessia-com-os-próprios-pés!" (BRIGO, 2020, p. 70).

A professora-trilheira-pesquisadora sentiu as contrações pulmonares na trilha ao respirar a pesquisa-caminhante, a qual não está orientada para a produção de "resultado de aprendizagem" frente aos professores e nem com os "objetivos de aprendizagens", mas para produzir algum movimento real, no presente e na presença, - "[...] que não deve ser rastreado até uma decisão individual, escolha e motivação" (MASSCHELEIN; SIMONS, 2017, p. 52) naqueles que ensinam matemática e nos artefatos (ferramentas, instrumentos, tecnologias e trilha-rias ${ }^{7}$ ) de seus ofícios. A experiência ${ }^{8}$ com a trilha elevou-se aos movimentos de

5 Em trilha, deslocou-se a nomeação de formação para (form)-ação. "Os parênteses indicam que a formação como dispositivo de fabricar-formar na trilha necessita ser suspensa, fazendo com que a "ação" assuma outras vozes para o "formar" quando se caminha em (com)-panhia. Já o hífen indica um possível deslocamento do formar para o deformar (transformar, mexer, alterar) ou como possíveis movimentos de deformação em encontros com professores." (BRIGO, 2020, p. 54).

6 São as participantes que foram cativadas para fazer a caminhada e fazer ressoar como "[...] sofrer, padecer, agarrar o que nos alcança respectivamente, aceitar, na medida em que nos submetemos a isso." (LARROSA, 2017, p. 99).

7 Palavra inventada para nomear as materialidades e imaterialidades que cada professora-trilheira carregou consigo enquanto caminhava.

${ }^{8}$ Expressa uma palavra-conceito-ideia que faz tremer e vibrar. É difícil de escrever, definir e identificar escapa de uma objetivação e produção, Larrosa (2017a). 
inspiração e expiração, tão importantes quanto a função do diafragma. Cá, na trilha, inspirando-me-nos e ex-pirando-me-nos. Quiçá, na trilha, uma formação-diafragma, acontecendo no e pelo estudo, um professor-estudante.

Um trilhar aberto onde o professor(a) tem espaço porque ele é também estudante.

Um espaço aqui, livre, liberado. Fora da extensão dos lugares concretos e dos territórios marcados. Espaço aberto, indeterminado. Por isso, o estudante [professor] vaga, divaga, vagabundeia. Extravagente, o estudante dá voltas e mais voltas, se move lentamente, se permite rodeios, se oferece paradas, se detém. (LARROSA, 2003, p. 19).

Disto, portanto, pensa-se que talvez, na costumeira trilha possamos pensar o educar como travessia, caminhada, numa tentativa de "encontrar o próprio passo, o próprio peso e a própria leveza," (SKLIAR, 2014, p. 159). Talvez, na costumeira trilha possamos produzir conhecimento, inventar percursos-rizomas e produzir caminhos para a de-(com)-posição de sujeito e objeto, isto é, "[...] de si e do mundo num movimento de coengendramento... [...] sem uma boa resposta, uma solução definitiva. Afinal, o que é mesmo conhecer? Como é que se produz conhecimento? Como é mesmo que se faz pesquisa?" (BARROS; MORSHEL, 2012, p. 62). Como é mesmo o estudar em uma trilha com professoras? Quais os ecos do estudar numa pesquisa-trilha com professoras que ensinam matemática nos anos iniciais do Ensino Fundamental?

\section{Primeira Paragem: uma vertente na Ilha nomeada "palavrar"}

Quando se está trilhando, não se sabe quando e onde será possível encontrar uma vertente de água potável na ilha, de modo que convém carregar um reservatório de água, para quando a sede surgir pelo caminho. E se na trilha se ouve algum barulho de água, ou se sente os pés molhados, convém parar e olhar atentamente para o chão, pois pode ser que haja alguma vertente nesse espaço. É preciso xeretar o espaço. E se aparece uma vertente com água, convém aproveitar o encontro, experimentar a água, bebê-la, senti-la e abastecer o reservatório. Entre um gole e outro, a língua é atravessada pelas gotas que se bebe, hidratando palavras e verbetes. A atenção para as vertentes pode fazer emergir palavras. 0 que era silêncio se faz ruído. "Murmúrio de vozes sem voz, gotejar de palavras. As palavras alheias e as próprias se confundem e o estudante trata de manter o limite de uma separação cada vez mais impossível". (LARROSA, 2003, p.71).

Palavrar, essa afetação que incorpora as unidades linguísticas de nossa língua portuguesa ao significado, que pode ser escrita ou falada, como modo de realizar-se por meio de palavras. É um ato que emerge com o trilhar-se, no "entremeio" do caminho, pelo caminhante, agora estudante, que presta atenção aos detalhes que surgem nesse modo de deslocamento. Concebe-se o termo palavrar como sendo a igualdade da inteligência conferida à raça humana, uma possibilidade incontrolável de se expressar verbalmente, e ainda, um acontecimento que incorpora as palavras como potência para problematizar "o sentido do que nos passa" (LARROSA, 2004, p. 296) e talvez, "produzir efeitos de sentido"(idem).

A busca por palavras vai além de uma questão terminológica e/ou estética, pois faz parte do risco que nos atravessa - autoras, nesse momento em que ocorre essa escrita e no encontro com referenciais teóricos. Enquanto estudantes que trilham suas palavras parecemIhe alheias, como se não fossem suas, mas também de ninguém. "As palavras alheias e as 
próprias se confundem e o estudante trata de manter o limite de uma separação cada vez mais impossível". (LARROSA, 2003, p. 71)

Tem-se a convicção de que as palavras são mecanismos de subjetivação, pois "[...] quando fazemos coisas com as palavras, do que se trata é de como damos sentido ao que somos e ao que nos acontece, de como correlacionamos as palavras e as coisas, de como nomeamos o que vemos ou o que sentimos e de como vemos ou sentimos o que nomeamos." (LARROSA, 2017, p. 16).

A atenção para com as palavras, o estilo delas e o modo como as combinamos na escrita - além de serem potência para as aventuras propostas - também "[...] determinam nosso pensamento porque não pensamos com pensamentos, mas com palavras, não pensamos a partir de uma suposta genialidade ou inteligência, mas a partir de nossas palavras." (idem). Nesse sentido, pode-se pensar que "os que escrevem são atravessadores de palavras; em seus corpos as palavras passam, ou cruzam, ou sufocam" (SKLIAR, 2017, p. 63).

Na paragem da vertente de água aprende-se:

- que a palavra e o pensamento são lugares de acontecimentos, pois ambos não podem ser controlados, vigiados e monitorados. "As palavras produzem palavras e as ideias produzem ideias. $E$ as palavras ou as ideias que se produzem nunca podem ser completamente previstas, prescritas, fabricadas." (LARROSA, 2004, p. 308).

- que os pensamentos voam, como pipas no céu, e as palavras ventam. Há potência do movimento nos pensamentos e nas palavras. Cada trilheiro(a) se depara com algumas palavras bem verdes, brotando, e com outras já balançando ou então maduras, já caídas, apodrecendo. Não se pode prever o modo como cada um irá tratá-las ou se irá olhá-las. Ou antes, se causaram detenção a certas palavras.

Então, aqui nesta paragem do artigo, duas palavras se destacam: UMA e TRILHA.

A palavra UMA é dobrada e espichada, e multiplicada expressa o ato de escrever com a emergência a alguém, com alguém, sobre alguém, "Começa a escrever e outra vez a distância entre ele [o estudante] e as palavras." (LARROSA, 2003, p. 69). Um laço mínimo com alguém para começar algo "[...] é preciso aprender qualquer coisa." (RANCIÈRE, 2017, p. 41). Alguma coisa que não está dada a priori, é indeterminada, em princípio, talvez um tipo de território de passagem e ou um lugar provisório, proposto como sendo "[...] algo como uma superfície sensível que aquilo que acontece afeta de algum modo, produz alguns afetos, inscreve algumas marcas, deixa alguns vestígios, alguns efeitos." (LARROSA, 2017, p. 25).

O estudante isola o que leu, repete-o, rumina-o, copia-o, faz variá-lo, recompõe-no, diz e contradiz o que leu, rouba-o, fá-lo ressoar com outras palavras, com outras leituras. Vai-se deixando habilitar por ele. Dá-lhe um espaço entre suas palavras, suas idéias, seus sentimentos. Torna-o parte de si mesmo. Vai-se deixando transformar por ele. E escreve. (LARROSA, 2003, p. 67).

Daí que "Escrever é um caso de devir, sempre inacabado, sempre em via de fazer-se, e que extravasa qualquer matéria vivível ou vivida. É um processo, ou seja, uma passagem de Vida que atravessa o vivível e o vivido." (Deleuze, 1997, p. 11). Logo, o exercício de escrita não se dá, portanto, "para demonstrar a verdade de uma história, para defender ideias ou conceitos, para render homenagens ou tributos, nem para consagrar pensamentos, ainda que 
algo de tudo isso possa habitar essa escrita" (KOHAN, 2015, p.18), mas o que interessa, antes é "a palavra no movimento múltiplo da vida, da escrita e da leitura, no que ela traz e origina de uma vida inteiramente pelas vidas por viver a partir das leituras dessas vida que se manifesta em palavras" (KOHAN, 2015, p. 18).

UMA, assim, se refere ao(s) acontecimento(s), ou seja, aquilo que acontece, cuja ocorrência é imprevista, e ao acontecer "[...] faz a diferença incompreensível e a ruptura inapropriável. E já não permite pensar a educação como um diálogo entre diversidades nem como mediação entre passado e futuro." (LARROSA, 2004, p. 206). É alguma coisa que "[...] não se pode fabricar" (Ibidem, 308), por isso "[...] não podem existir políticas de produção de acontecimentos e só se podem favorecer suas condições" (Ibidem, p. 308). E, talvez, "[...] um lugar a que chegam as coisas, como um lugar que recebe o que chega e que, ao receber, Ihe dá lugar" (Idem, 2017, p. 25), ou ainda, "[...] é criar uma pausa, um instante, é ligar-se com o presente [...]" (FLORES, 2015, p. 242). De transformação, de tentativa, de um movimento pessoal que acontece com o sujeito em (ex)-posição "[...] nossa maneira de '(ex)-pormos', com tudo o que isso tem de vulnerabilidade e de risco." (LARROSA, 2017, p. 26)

Passemos a TRILHA. Convocar um trilhar(-se) é não colar-se ou fusionar-se, mas antes avizinhar-se, entrar em relação com o outro e consigo mesmo. É um chamado à trilha de um modo de "[...] se colocar diante das diferenças, das diversidades, das alteridades, daqueles que, não estando previstos e previsíveis nos caminhos certos dos experimentos, te acenam para a estrangeiridade de lugares, de eventos e de situações." (LEITE, 2011, p. 16). Trilhar como possibilidade de deslocamento, de ir junto e de estar em companhia (com alguém e ou alguma coisa). Trilhar para estudar, pois que

Só assim o estudante pode escapar, ao menos provisoriamente, à captura social da subjetividade, a essa captura que funciona obrigando-o a ler e a escrever, a ler-se e a escrever-se, de um modo fixo, com um padrão estável. (LARROSA, 2003, p. 87)

O sujeito da trilha é um sujeito "(ex)-posto", em especial, pelos exercícios de "travessia" e "risco". E, talvez, de-(formar) ${ }^{9}$ e des-(modelar).... Sejam modos outros de ir pelo meio, pelo] entre $\left[{ }^{10}\right.$, com entradas abertas, um devir em curso, perambulando. Experimentarse, colocar-se em outro espaço e, então, estudar. Este sujeito se aproxima do que se nomeou de professor-flanêur (MACHADO e FLORES, 2018), pois que caminhando, há que se tornar um flanêur. Que olha o que pergunta, perguntando, estuda e, ao fazê-lo, olha a si próprio de dentro.

Estar em trilha, no encontro com o que nos impele a pensar, quase como uma necessidade de dar razão àquilo que nos capturou no e pelo caminho, e não no desencadear do pensar por reconhecimento, mas por arrombamento de algo estranho que é sentido por

\footnotetext{
9 “Os parênteses indicam que o formar - como sinônimo de dar certa configuração, um certo formato - na trilha necessita ser suspenso de seu uso habitual e, talvez, essa ação possa assumir outras utilizações do formar quando se caminha. Já o hífen indica um possível deslocamento do formar para o deformar - transformar, mexer, alterar - ou como possíveis movimentos de contra-formar em encontros com professores, com os próprios pés, com o corpo." (BRIGO, 2020, p. 25).

10 “Entre as coisas não designa uma correlação localizável que vai de uma para outra e reciprocamente, mas uma direção perpendicular, um movimento transversal que as carrega uma e outra, riacho sem início nem fim, que rói suas duas margens e adquire velocidade no meio." (DELEUZE; GUATTARI, 1995, p. 37).
} 
quem caminha (sentido em diferentes afetividades por cada sujeito) e que seja, ao mesmo tempo, impulsionador. Aprender é ir além do que o exercício empírico do caminhar apresenta, como sugere Deleuze (2006).

Ser e estar em uma trilha refere-se ao movimento de um grupo (figuras pedagógicas) que aceita o convite para caminhar como uma possibilidade de deslocamento, de ir junto e de estar com alguém e/ou alguma coisa por lugares provisórios que não estão dados a priori, pois sempre estão em via de fazer-se pelo corpo com o andar, o olhar, o pensar, o parar, o sentir, o ouvir, o falar, o silenciar, o cheirar, o tatear, o fotografar ou o perder-se.

Feito isto, que se incorpore um ethos (político e pedagógico) de ser e estar no mundo, de ser e estar na escola e de ser e estar na matemática (na matéria). Modos de se relacionar consigo, com os outros, com o mundo e com a matéria, e logo, de cuidar de si, dos outros, do mundo e da matéria.

Ora, parece "que para aprender e para ensinar é importante estar atento, mas também estar atento em movimento" (KOHAN, 2017, p.59). Com isso, o aprender está na dimensão de quem caminha, do devir-trilha e dos modos outros de ir pelo meio, pelo ]entre[ sem um traçado objetivo (apenas com início e fim), mas que pode acontecer com o sujeito em sua experiência de trilhar-se. Para Deleuze, o aprender "[...] vem a ser tão-somente o intermediário entre não-saber e saber, a passagem viva de uma o outro." (DELEUZE, 2006, p. 161). A diferença entre aprender e estudar está na ação do sujeito que estuda e/ou aprende, pois "[...] aprender tem a ver com fazer (se aprende fazendo ou se aprender a fazer), enquanto estudar tem a ver com suspender o fazer, a vontade de fazer e demorar-se no olhar ou no contemplar."(LARROSA, 2018, p. 441).

\section{Segunda Paragem: um Olho d'água da llha, "o estudar"}

O movimento que se faz com os pés no chão possibilita prestar atenção em detalhes que, muitas vezes, passam despercebidos com outros tipos de deslocamentos. Exploram-se outros espaços. Habitam-se outros espaços. Espaços fora dos territórios marcados. Espaços abertos. Espaços que oferecem paradas, que se detêm. De repente, no chão, acha-se um olho d'água. Aproveita-se o encontro para fazer uma parada. Molha-se. Refresca-se o corpo. E no refrescar dele se sente arrepios. Arrepios que tremem o corpo da professora-trilheiraestudante e fazem com que ela mergulhe no olho d'água. Entrega-se, misture-se a ele. Entranha-se no olho d'água, intensamente. Imerge-se na água e na imersão do corpo, lembranças: do estudar, de uma outra entrega tão intensa quanto mergulhar em um olho d'água!

Estudar e estudar e estudar! Um estudo que significa tanto um tipo de atividade que se realiza quanto um espaço (que pode ser o quarto de estudo, ou o olho d'água no caminho da trilha). O estudo, portanto, como uma forma de vida (BÁRCENA ORBE, 2019, p. 41).

Mergulha-se e entrega-se ao estudo. Faz isso por vontade própria, pelo desejo de simplesmente estudar por estudar, estar em estudo, de ser estudo e de viver o estudo. Mas o estudo requer "[...] atenção, humildade, repetição, paciência, certa obediência inclusive, um certo deixar-se mandar pela matéria mesma de estudo" (LARROSA; RECHIA, 2018, p. 158).

A professora-trilheira-estudante sentiu a diferença] entre[:

] encontrar um olho d'água e mergulhar em um olho d'água [;

] ler um livro e estudar um livro [;

] ler um artigo e estudar um artigo [; 
] ler um documento normativo e estudar um documento normativo [;

] ler as ideias de um autor e estudar as ideias de um autor [; ... (BRIGO, 2020, p. 88)

Eis nosso desafio, nossa (ex)-posição: estudantes (caminhantes), Estudar (trilhar)!

Estudantes que formam ou transformam suas próprias palavras, na relação com as palavras que são lidas e estudadas a partir dos outros. "As que ele lê, as que ele escreve. Suas próprias palavras. As que nunca serão suas." (LARROSA, 2003, p. 61). Caminhantes que deformam ou transformam a Ilha num outro espaço, numa outra Ilha.

O estudante é um ser sempre presente, não está orientado a uma finalidade exterior, não está preocupado com o tempo passado e futuro. "Nada o ameaça, nada o distrai. Nenhuma tarefa programada, nenhuma matéria, nenhuma obrigação se misturam com seu estudo." (LARROSA, 2017b, p. 247). O estudante encontra-se "Estendido no umbral do presente". (NIETZSCHE, 1977, p. 53-54 apud LARROSA, 2017b, p. 247).

Eis sobre o estudar:

Estudar é prestar atenção a alguma coisa.

Estudar é uma maneira particular que cada um de nós pode encontrar quando repete, memoriza, escreve e exercita uma matéria.

Estudar: ler perguntando. Percorrer, interrogando-as, palavras de outros. (LARROSA, p.99, 2003).

Estudar é movimentar perguntas, estendê-las, aprofundá-las, desfiá-las, rasgá-las.

Estudar "[...] significa insistir sobre o mundo a partir de uma técnica determinada... [...] exercitar-se em alguma disciplina em particular que nos abra caminho para o mundo." (LARROSA, 2018, p. 440).

Estudar é voltar-se para si mesmo, é fechar os olhos e os ouvidos para todo o resto, fixar-se unicamente no estudo "fabricar-se, com seu próprio corpo, uma espécie de campânula de vácuo que nada consegue atravessar." (LARROSA, 2017b, p. 248).

Estudar é uma forma de exercitação que supõe uma grande fatiga. ${ }^{11}$ (BÁRCENA ORBE, 2019, p. 53).

Pois que, então, repetimos: estudar como forma de vida, que não seria senão, como assinala (BÁRCENA ORBE, 2019), "a busca, a prática, a experiência pelas quais o sujeito efetua em si mesmo as transformações necessárias para ter acesso à verdade" (FOUCAULT, 2004, p.19). "Deste modo, o estudo liberta-se da tristeza que o desfigurava, para regressar à sua verdadeira natureza: não a obra, mas a inspiração, a alma que se alimenta de si própria." (AGAMBEN, 1999, p. 56).

No olho d'água, o caminhante e o estudante, em si mesmo, se entregam de corpo e alma. $O$ caminhante se entrega ao que pede o caminho. $O$ estudante se entrega ao que pode 0 estudo. $O$ trilhar e o estudar se atravessam, se misturam, se abrem e se multiplicam. Ambos fogem do formar-modular. Ambos percebem que o fim do estudo pode ser nunca alcançado, e fascinados pelo olho d'água permanecem em estudo, estonteados.

Eis a ideia de uma formação-trilha pelo estudar.

\footnotetext{
${ }^{11}$ Do original: Estudiar es una forma de ejercitación que supone una larga fatiga.
} 


\section{Terceira Paragem: um furo na Ilha, um Grupo de Estudo}

Pelas palavras e ideias expressadas até aqui, neste artigo, cabe-nos, então, chamar a atenção para um GRUPO: um conjunto de professoras que ensinam matemática que, pela atenção, manifestam interesse com alguma(s) coisa(s)em comum, colocando-as em ESTUDO. A expressão "Grupo de Estudo" atravessou a trilha e "[...] indica um grupo de professoras atento e interessado ao estudo, e também, que o ato de estudar, acompanhado de alguma coisa, serve de potência para os encontros." (BRIGO, 2020, p. 60)

Professoras participantes cativadas para a trilha. Figuras pedagógicas que habitam a trilha, a escola, o mundo. Que traçam pegadas, deixam marcas, são marcadas, produzem e são produzidas na trilha e com a trilha. Que deixam o que sabem e se permitem atravessar por aquilo que não sabem. Aquelas que passam signos, palavras, textos, sabores, que ensinam matemática. Professoras que ensinam a viajar e convidam a viajar. Aquelas figuras pedagógicas que se permitem saírem de si mesmas para sair em excursão pelo mundo (SKLIAR, 2014). Aquelas que registram em seus diários as expressões dos acontecimentos que se fazem no caminhar, nos encontros atravessados de atos e afetos.

Assim, grupo de estudo: a preposição "de" estabelece uma relação de ação entre elas, de modo que a segunda palavra marca a ação da primeira, e vice-versa. Com isso, pretendese indicar um grupo de professoras que se articulam pelo estudo.

O estudo se faz de desfazer-se: não há mais que o risco, entre ler e escrever, o desconhecido que volta a começar, algo (se) passa, o gesto de apagar o que acaba de ser lido ou escrito para que a página continue em branco, ainda por ler, por escrever. (LARROSA, 2003, p. 113).

Assim, o grupo de estudo seja como um furo na llha. Seja visto por quem anda nela e possibilita exercícios de pensamentos, sobretudo nos sujeitos que atuam com a formação de professores - essa ação coletiva de professores para estudar alguma coisa em comum. Quiçá, disso, uma desativação das tão fixadas expressões "formação continuada", "formação em serviço" e "formação permanente" usadas nos discursos e práticas dominantes para nomear a "formação docente". O que carregam são marcas de "incompletude" profissional do professor; de um profissional "inacabado", que necessita de "formação permanente", de "reciclagem" para atualizar-se ao mercado de trabalho; de um sujeito incapacitado para exercer sua "profissão", que necessita de "capacitação constantemente", que está desatualizado, precisando se atualizar. Enfim, tantas outras expressões que desvalorizam o ofício do professor. O ofício de professor tem a ver com artesania (LARROSA, 2018). É um modo de ser e de atuar, um hábito, um costume cotidiano e, talvez, correm-se grandes riscos de deixar de ser artesanal "por isso, fale-se constantemente dos conhecimentos, das competências, da eficácia ou da qualidade do professor, mas não mais de suas mãos, seus gestos, ou suas maneiras" (LARROSA, 2018, p. 41).

Para isso, pensando em uma possibilidade entre tantas, arrisca-se a deslocar a formação "continuada" de professores para um Grupo de Estudo. Com isso, talvez, ler, estudar, escrever, trilhar, palavrar, encontrar e conversar, regularmente na escola, ou em qualquer outro espaço, abrindo-se em trilhas, colocando-se em estudo. Se "ser-estar em uma trilha é a parte mais interessante" (BRIGO, 2020, p. 178), que fique o convite a seguir caminhando, contando e re(contando) os seus efeitos, pois nossa afetuosa aposta é que cada trilha evocada seja potência para abrir e re(abrir) o mundo (da Educação Matemática). 
Quando experimentamos habitar o mundo com os próprios pés, trilhar-se, ou ainda, inventar uma pedagogia pelo caminhar, ou ainda, uma pé-da-gogia, o verbo estudar se estabelece no] entre[, na experiência. Ora, que resistências podem ser maquinadas num Grupo de Estudo. Estudar é resistir? Ou resistir é estudar? Porque isso tem a ver com um movimento de recusar a si mesmo, professor formado, em formação, em continuidade, esse que nos habita e nos devora, e que é, ele mesmo, nosso algoz. Então levar em consideração que a força de um grupo de estudo pode ser a renovação de modos de conexões na educação matemática, que não estão dadas, mas que precisam ser inventadas por nós, humanos. $\mathrm{O}$ que isso tem a ver com a invenção de uma formação-trilha-estudante? O que vem a ser o chamado para o GRUPO DE ESTUDO?

A título de exemplo de um Grupo de Estudo destacamos alguns exercícios desenvolvido na pesquisa de BRIGO (2020). Um dos exercícios de estudo utilizou as Barrinhas Cuisineire. Esse material manipulável estruturado foi colocado sobre a mesa para estudo por uma das participantes ${ }^{12}$ e com ele o convite a inventar um objeto utilizando as Barrinhas de Cuisenaire. Dentre os objetos inventados pelas professoras-trilheiras-estudantes teve-se: gato, girafa, girassol, casas, jardins, pipas e o sol, conforme ilustra foto abaixo:

Figura 1 - Inventos das professoras-trilheiras-estudantes

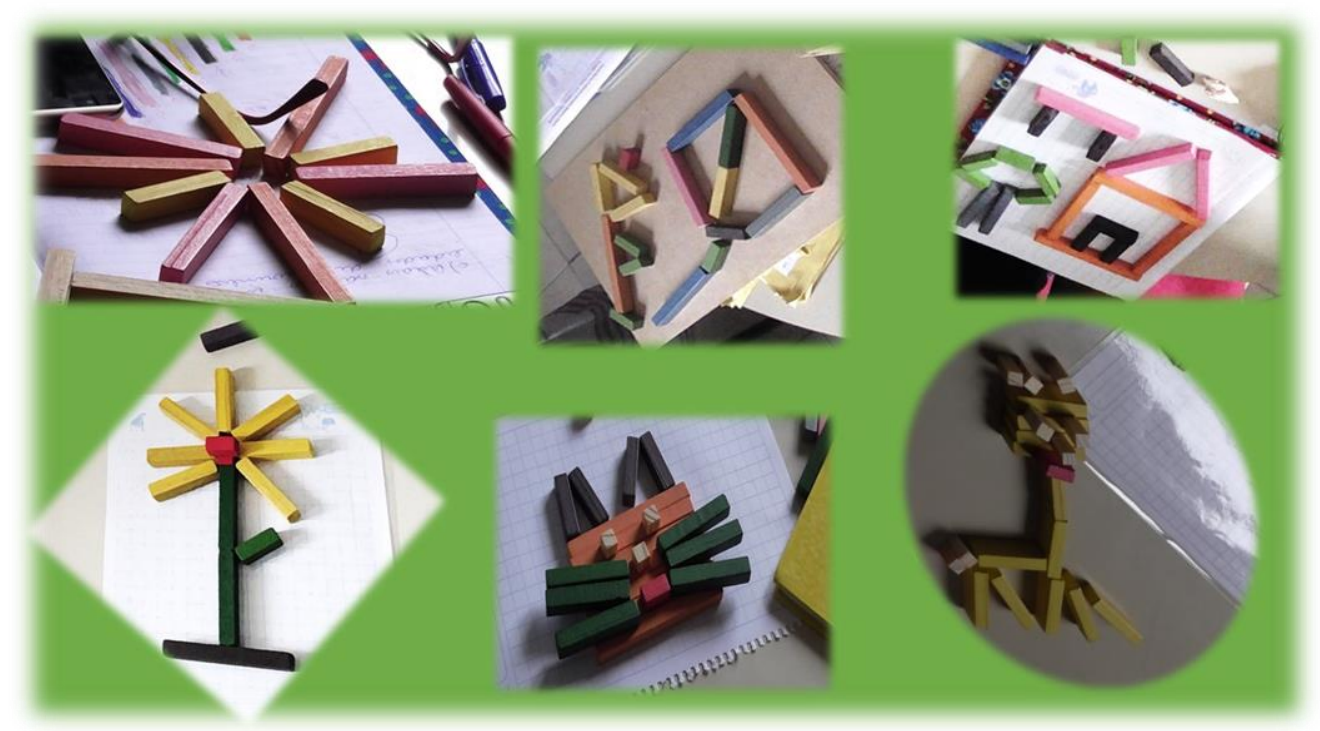

Fonte: Arquivo pessoal.

Cada invento demandou uma quantidade de barrinhas e um tipo de barrinha e com isso pensou-se e estudou-se: Quantas barrinhas cada participante utilizou? Quais os tipos de barrinhas que cada participante utilizou? Qual a maior e a menor barrinha utilizada no invento? Qual objeto inventado pelas participantes utilizou mais barrinhas? Se a barrinha da unidade, por exemplo, custava um real, quanto gastou-se com o invento? Qual o perímetro, área e volume do objeto inventado? Pensamentos que envolvem a escola, o escolar, a matéria (a língua artificial) e com eles "ações que suscitam: expressar, arriscar e duvidar: "Perímetro é

\footnotetext{
12 "Nossas pegadas eram atravessadas pelas "cargas" das sacolas, sobretudo com o que cada participante carregava dentro dela. Assim, antes de iniciar o estudo de cada encontro, o primeiro exercício era pensar acerca das trilharias que cada uma tinha carregado. Para isso, cada participante era convidada a colocar sobre a mesa o que havia levado para o encontro de (form)-ação." (BRIGO, 2020, p. 127)
} 
a soma dos lados. Não?"; escolher e considerar: "O teu, tu vais considerar tudo, não tem nada dentro"; entender, estranhar e problematizar: "[...]Como eu vou calcular o perímetro de um círculo?" (BRIGO, 2020, p. 166).

Portanto, ecos de um outro espaço, de um espaço em que o estudo problematiza e em que o conhecimento matemático é colocado como:

\begin{abstract}
aprender por interesse e não para um fim específico: "A gente não ensina para as crianças, mas que bom que a gente estudou e agora sabe!"; ser e ter tempo (livre), assumir a responsabilidade do que se ensina para a geração mais nova: "Eu penso que perímetro e área têm mais a ver com os conteúdos do $3 \circ$ e 4 ano. A gente teve dificuldade em entender área e perímetro, quase ficamos a tarde inteira vendo o que era o perímetro do objeto. Imaginem as crianças do segundo ano..."; o despertar para a possibilidade de que todos podem aprender e gostar de matemática: "Meninas, eu não sei vocês, mas eu não sou muito boa em calcular de cabeça. Já meu marido e minha filha calculam rapidinho. Na verdade, eu nunca gostei de matemática, mas estou gostando do que a gente está estudando no grupo". (BRIGO, 2020, p. 167168)
\end{abstract}

Cabe destacar também que outros materiais manipuláveis foram objetos de estudo do grupo, em especial, citamos o Tangram, o Ábaco, o Material Dourado e as Fichas Escalonadas. Com esses materiais estudamos muitos conceitos matemáticos que atravessam o ensino de matemática nos anos iniciais do ensino fundamental, como por exemplo: número e suas funções; sistemas numéricos; sistema de numeração decimal; operações no sistema de numeração decimal; múltiplos e divisores; simetria; figuras planas e espaciais; lugar geométrico; perímetro; ângulos; área; tabelas; relações por atributos; relações numéricas; sequências. Ao colocar esses materiais sobre a mesa e se fazer com eles acontecimento trilhou-se fora dos caminhos marcados, suspendeu-se certos usos e com isso cada professoratrilheira-estudante- pode inventar, compartilhar e estudar outras coisas "[...] profanar os usos de um material manipulável e estruturado há muito limitado por algo regrado, préestabelecido."(BRIGO, 2020, p. 159)

Para além dos materiais manipuláveis, no caminhar da trilha, propôs-se pensar em possíveis conexões entre a arquitetura açoriana e o ensino de geometria, fazendo das imagens lugar de potência para o exercício de pensamento.

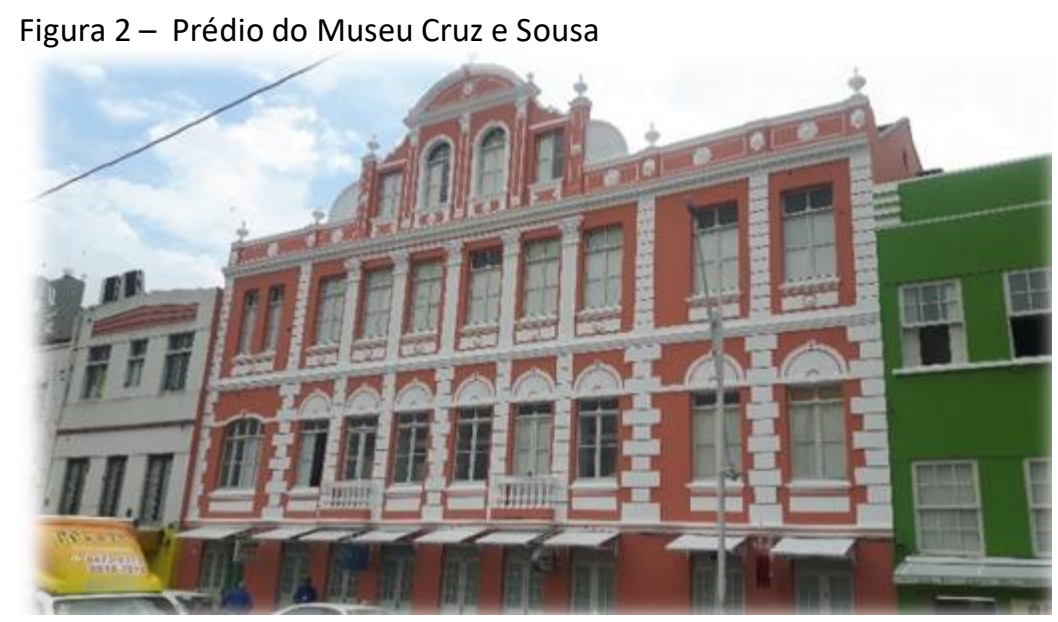

Fonte: Arquivo pessoal. 
Figura 3 - Prédio do Museu Cruz e Sousa

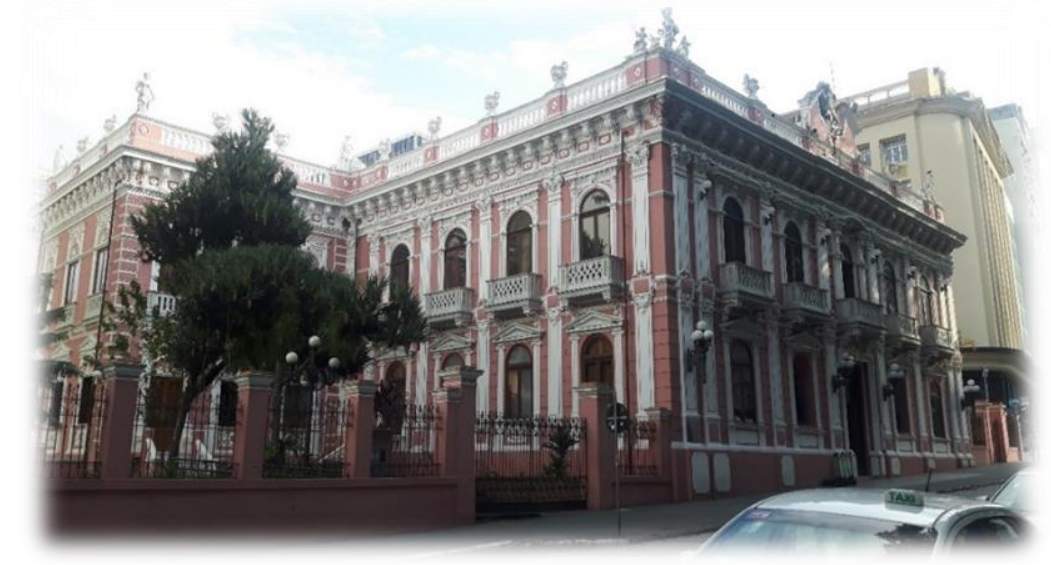

Fonte: Arquivo pessoal.

As imagens estudadas fizeram com que as trilheiras-estudantes olhassem com atenção para a arquitetura local, seu colorido, seu encanto, seus detalhes. Detalhes das janelas, portas, fachadas e beirais das casas, das igrejas, enfim, dos conjuntos arquitetônicos de Florianópolis, que preserva um acervo histórico dos séculos XVIII e XIX. Pensou-se que a arquitetura açoriana, com sua forma, função e construção, pudesse despertar o interesse das demais trilheiras que estavam caminhando, pois também era sabido que "a arquitetura histórica de Florianópolis equivale aos monumentos existentes em todas as cidades que guardam construções como testemunho das gerações e dos fatos do passado e como referência humanizadora do tempo presente." (CARONIA, 2012, p. 10). Colocou-se a arquitetura e a matemática num mesmo campo de interesse, de saberes e de práticas e, que, historicamente, tanto produzem discursos e verdades, quanto são efeitos para subjetividades docentes e práticas pedagógicas. Enfim, detalhes que compõem nossas vidas, nossas práticas e nossos ofícios...saberes que atravessam nossas vidas e que, muitas vezes, se naturalizam, a tal ponto que não percebemos os pormenores que os compõem.

Além das imagens, nós pomos a estudar com alguns livros que atravessam o ofício, tais como, Florianópolis: História e Arquitetura, que apresenta muitas fotos da arquitetura açoriana e seus detalhes históricos e culturais; o livro da Proposta Curricular da Rede Municipal de Ensino de Florianópolis, que apresenta os conteúdos propostos para cada ano e cada disciplina; e os livros didáticos da Coleção Saber Matemática, do 10 e 2 을 ano, das autoras Kátia Stocco Smole, Maria Ignez Diniz, Vlademir Marim utilizados pelas professoras na escola. Com esse exercício, estudamos algumas materialidades, que atravessam o ofício daqueles que ensinam matemática e o modo como a arquitetura açoriana está ou não colocadas nelas. As professoras-trilheiras perceberam e compartilharam que ora a arquitetura açoriana aparece é presença (em imagens e na arquitetura local) e ora desaparece é ausência (nos documentos normativos e livros didáticos). A presença e a ausência da arquitetura deixaram-nas inquietas, evidenciando que ainda precisamos continuar caminhando e problematizando certas materialidades indicadas para o ensino de matemática, uma vez que "que a arquitetura açoriana não se faz presente nos documentos normativos ou livros didáticos, embora sua presença encante e fascine quem caminha atentamente pelas ruas da cidade, olhando os detalhes de sua arquitetura." (BRIGO, 2020, p. 117)

Se por um lado, em uma (form)-ação de professoras, a matemática foi apresentada como uma matéria de estudo, colocada sobre a mesa por meio de exercícios envolvendo 
materialidades que compõem os artefatos do ofício, por outro, foi disparadora de afetos, memórias e liberdade para compartilhar o que se passa quando se estuda em um grupo de professoras e se ouve o dizeres de uma professora-trilheira sobre os efeitos de um GRUPO DE ESTUDO:

Eu me afeto profundamente com essa palavra. [...] Eu quero falar das palavras Grupo, Estudo e de Grupo de Estudo. Eu comecei a ver com meus estudantes, naquele momento como auxiliar de ensino trabalhando com a matemática, eu comecei a me projetar no meu passado, no meu passado com tantas dificuldades na matemática, de por que eu olhava para a matemática como algo tão difícil para mim, por que que eu nunca consegui aprender matemática. Porque os estudantes me davam as respostas. Tudo o que os estudantes me falavam era o que eu também falava enquanto estudante, daí eu me encontrei com algumas pessoas. Jussara, você é extremamente importante nesse processo, porque, quando eu precisei escrever sobre um trabalho que eu não acreditava, você fez eu olhar para aquilo e ver que aquilo era muito legal e que tinha tanta coisa que eu trabalhava ali que eu não sabia, e aí eu me vi professora de verdade. Depois disso, as pessoas da escola começaram a olhar para o trabalho da professora auxiliar, que é um trabalho tão difícil, um trabalho tão solitário, que às vezes a gente planeja para um monte de coisas e para nada ao mesmo tempo. Naquele período mãe, com um bebê, eu comecei a estudar de novo e aquilo me jogou para quatro concursos e eu passei nos quatro. Quando eu me vi supervisora na maior escola da Rede, eu pensei: será que eu vou dar conta disso? Eu fui muito bem recepcionada por essa escola. E a gente começa a fazer um trabalho de formiga, um trabalho que eu sempre coloquei à mesa, o que eu conseguia e o que eu não conseguia. Eu comecei a me revelar das coisas que eu conseguia, e das coisas que eu precisava estudar e olhar para um trabalho. Assim a gente começou a fazer um grupo de trabalho, um grupo de pessoas, e é assim que eu acredito, é por isso que é sobre isto que eu vou escrever no meu projeto de mestrado. Eu acho que não tem mais como a gente fazer um trabalho sem um grupo de estudo, sem estudar coisas, sem pensar nas coisas, o professor precisa de parceiros e a supervisão precisa de parceiros. Meu trabalho não funciona se eu não tiver os professores como parceiros, com uma equipe pedagógica parceira, com uma direção parceira. Eu acho que um grupo de estudo, ele impulsiona a gente para aquilo que a gente mais tem dificuldades e para aquilo que a gente pode, a gente consegue ser protagonista e consegue ser coadjuvante num grupo desses. Quando a gente está falando de práticas compartilhadas, nem sempre as pessoas estão disponíveis, porque a gente tem que colocar e mostrar. Se colocar no grupo perante as coisas, tem coisas que a gente não sabe, enquanto supervisora pedagógica, me parece que, às vezes, as pessoas esperam que uma supervisora, que ela saiba muitas coisas. Eu cheguei aqui não sabendo muitas coisas e eu aprendi demais. Eu aprendi coisas pessoais que me refez Renata diferente, às vezes, eu acho que eu era muito boazinha, às vezes, eu acho que eu era muito ruinzinha. $E$ a gente vai se fazendo. $A$ gente está disponível para aprender. Então, eu sou eternamente grata por essa escola, porque aqui eu aprendi muitas coisas. (BRIGO, 2020, p. 125) 
Em uma formação-trilha abre-se espaço para que as outras trilheiras-estudantes digam o que acontece quando se caminha-estuda "[...] faz retornar como estudante e como professora que atuou 15 anos em sala de aula. [...] Aprendemos juntas, apresentamos dificuldades que compartilhávamos umas com as outras, assim foi possível perceber que, na trilha da (form)-ação, não estava sozinha." (BRIGO, 2020, p. 165).

E ainda, em uma formação-trilha não é possível prever

\author{
o que acontece em uma trilha; \\ quem será cativado para trilhar; \\ o que cada trilheira(o) carregará consigo; \\ os afetos e desafetos de cada caminhante na trilha; \\ as marcas da trilha; \\ as lembranças da trilha; \\ o tremer; \\ o trilhar. (BRIGO, 2020, p. 86)
}

\title{
5 Quarta paragem: de uma valeta ao elogio
}

“Olhe aquela valeta! Que valeta! Que valeta estranha! O que será que passa nela? O que será que já passou por ela? O que será que tem nela? Esqueça isso! Contemple a valeta estranha nomeada de "elogio"." (BRIGO, 2020, p. 56)

A título de exemplo de um grupo de estudo, referimo-nos a pesquisa realizada por Brigo (2020). Com ela, um grupo de professoras que ensinam matemática reuniram-se para fazer uma trilha-estudo. A ideia de trilha compunha uma ideia de elogio ao estudo. Antes de uma Trilha com professoras a noção de elogio carregava um significado de tornar grandiosos as qualidades ou os atributos de alguém ou de alguma coisa. No entanto, na trilha, a noção de elogio foi composta por outros ecos, em especial, para "elogiar alguma coisa significa um momento fúnebre, ou ainda, um momento que indica que alguma coisa corre risco de morte." (BRIGO, 2020, p. 56)

Ora, um estudo, às vezes, se apresenta solitário e exige refúgio, tempo, interesse e atenção. No entanto, outras vezes, se apresenta de forma compartilhada, exigindo um grupo de pessoas e um interesse comum. Daí que, trilhar-se, quem sabe, possa ser uma prática e um exercício educacional que envolve não só pessoas, mas areia, mar, olho d'água, terra, caminho, pedras ...., estudo.

Quantas coisas se passam em uma formação-trilha, habita-se o mundo com os próprios pés, esquivando-se de estacas, fugindo de trilhos, inventando ilhas, adentrando outros espaços, cativando-se à (com)-panhia de outras trilheiras-professoras-estudantes, sentindo a potência do livre, de ser livre, de estar livre, de estar ao ar livre, de viver ao ar livre...

Assim, um trabalho de pesquisa com formação de professores não é, tão somente, dar voz ao outro, escutar o outro, representar o outro, escrever o outro, ler o outro. Que disso, também, não é criar uma história de metáforas e analogias para falar sobre o que outro faz, deveria fazer, sobre sua constituição e subjetividade. Ao contrário, suspeitamos que algo pode acontecer num entrecruzamento de trilhas: escuta de futuro e histórias de vida. E pensamos, portanto, que o estudar pode ser a potência do trabalhar COM professores considerando seu ofício. 
Enfim, que, pelo estudar exercita-se o silêncio, habita-se espaços e trajetos, cria-se trilhas, num ato solitário e ou em (com)-panhia, onde matemática e o ensino da matemática aparecem como problemáticas de estudo.

\section{Referências}

AGABEM, G. Ideia da Prosa. Edições Cotovia, Ltda, Lisboa, 1999.

BÁRCENA ORBE, F. La intimidad del estudio como forma de vida. In Ediciones Universidad de Salamanca / cc by-nc-nd Teri. 31, 2, jul-dic, 2019, pp. 41-67.

BRIGO, Jussara. FLORES, Claudia R. O conto da panecástica: a Ilha dos explicadores desiguais e/ou dos ensinadores iguais. Revista EM TEIA, Pernambuco, V. 10, no 3, p. 1-17, 2019.

BRIGO, Jussara. Uma trilha com professoras que ensinam matemática: diários e encontros. Tese de Doutorado. Pós-graduação em Educação Científica e Tecnológica. Universidade Federal de Santa Catarina, Florianópolis, 2020.

CARONIA, Anthony. Florianópolis: história e arquitetura. São Paulo: Escrituras, 2012.

DELEUZE, Gilles. Crítica e Clínica. Trad. de P. P. Pelbart. São Paulo: Ed. 34, 1997.

. Diferença e Repetição. 2ae ed. Rio de Janeiro: Graal, 2006.

. “¿Que és un dispositivo?” In: Michel Foucault, filósofo. Trad. de Wanderson Flor do Nascimento. Barcelona: Gedisa, 1990, p. 155-161.

FOUCAULT, Michel. "Sobre a história da sexualidade". In: Microfísica do poder. Trad. de Roberto Machado. 27ạ ed. Rio de Janeiro: Graal, 2009a, p. 243-276.

. Microfísica do poder. Rio de Janeiro: Graal, 1990.

. A hermenêutica do sujeito. São Paulo, Martins Fontes, 2004.

FLORES, C. R. "Entre Kandinsky, Crianças e corpo: um exercício de uma pedagogia pobre". Zetetiké, v. 23, n. 1, p. 237-252, 2015.

KOHAN, Walter O. O mestre inventor: relatos de um viajante educador. Belo Horizonte: Autêntica, 2015.

LARROSA, Jorge. Estudar=Estudiar. Trad. de Tomaz Tadeu e Sandra Corazza. Belo Horizonte: Autêntica, 2003.

. Linguagem e educação depois de Babel. Belo Horizonte: Editora Autêntica, 2004.

Elogio da escola. Belo Horizonte: Editora Autêntica, 2017.

Tremores: escritos sobre experiência. Belo Horizonte: Autêntica, 2017a.

Pedagogia profana: danças, piruetas e mascaradas. Belo Horizonte: Autêntica, 2017b. 
. Esperando não se sabe o quê: sobre o ofício de professor. Belo Horizonte: Autêntica, 2018.

; RECHIA, Karen. [P] de Professor. São Carlos: Pedro e João, 2018.

LEITE, César Donizetti Pereira. Infância, experiência e tempo. São Paulo: Cultura Acadêmica, 2011.

LEMOS, Flávia C. S; SILVA, Alyne A.; SANTOS, Daniele V. "Subverter". In: FONSECA, T.; NASCIMENTO, M.; MARASCHIN, C. (Orgs.). Pesquisar na diferença: um abecedário. Porto Alegre: Sulina, 2012.

MACHADO, Rosilene Beatriz; FLORES, Claudia Regina. Irene vista de dentro ou, das andanças erráticas de um professor-flanêur. Revista de Educação Matemática e Tecnológica Iberoamericana, v. 9, n. 2, 2018

MASSCHELEIN, Jan. "E-ducando o olhar: a necessidade de uma pedagogia pobre". Educação e Realidade, v. 33, p. 35-48, 2008.

RANCIÈRE, Jacques. O mestre Ignorante: cinco lições sobre a emancipação intelectual. 3 a ed. Trad. de Lílian do Valle. Belo Horizonte: Autêntica, 2017.

SKLIAR, Carlos. O ensinar enquanto travessia: linguagens, escritas, leituras e alteridades para uma poética da educação. Salvador: EDUFBA, 2014.

SKLIAR, Carlos. Desobedecer (a desobediência da linguagem). In: COSTA, L.B,; BANDEIRA, L.V.V.; CORRÊA, T.M. (Orgs.). Estátuas de nuvens: dicionário de palavras pesquisadas por infâncias. Porto Alegre: Sulina, 2017. 